Análise Espacial dos Condicionantes da Criminalidade Violenta no Estado de Minas Gerais Wagner Barbosa Batella, Alexandre Magno Alves Diniz

\title{
ANÁLISE ESPACIAL DOS CONDICIONANTES DA CRIMINALIDADE VIOLENTA NO ESTADO DE MINAS GERAIS
}

\section{Spatial Analysis of Violent Crime Determinants in Minas Gerais State}

\author{
Wagner Barbosa Batella \\ Mestre em Geografia pelo PPGG - TIE (PUC MG) \\ Doutorando em Geografia - UNESP (campus de Presidente Prudente) \\ Presidente Prudente - SP \\ wbatella@gmail.com \\ Alexandre Magno Alves Diniz \\ Professor do PPGG - TIE (PUC MG) \\ Belo Horizonte - MG \\ dinizalexandre@terra.com.br
}

Artigo recebido para publicação em 19/09/2009 e aceito para publicação em 01/04/2010

RESUMO: $\quad$ O fenômeno da criminalidade desponta neste início de século como um dos principais problemas vividos pelos habitantes das grandes cidades. Diversas ciências têm se dedicado ao estudo deste tema, mas somente nas últimas décadas a Geografia vem explorando a dimensão espacial da criminalidade através de uma sub-disciplina denominada Geografia do Crime. No escopo desta perspectiva surgem diversas contribuições para o estudo espacial da criminalidade. Este trabalho explora a distribuição espacial dos crimes contra pessoa e contra o patrimônio no Estado de Minas Gerais e, na sequência, analisa os condicionantes desta criminalidade. Para isso, faz-se uso de técnicas de mapeamento, com auxílio dos Sistemas de Informações Geográficas, e de estatística espacial.

Palavras-Chave: Geografia do Crime. Condicionantes da criminalidade. Análise espacial. Sistemas de informações geográficas. Minas Gerais.

ABSTRACT: The phenomenon of crime rises in the beginning of this century as one of the main problems experienced by the inhabitants of large cities. Various sciences have been devoted to the study of this subject, but only in recent decades, the geography has been exploring the spatial dimension of crime through a sub-discipline called Geography of Crime. In the scope of this approach are several contributions to the study of spatial crime. This paper explores the spatial distribution of crimes against persons and property in the State of Minas Gerais, and in response, examines the determinants of this crime. For this, it uses mapping techniques, with aid of geographic information systems, and spatial statistics.

Keywords: Geography of Crime. Determinants of criminality. Spatial analysis. Geographical information systems. Minas Gerais. 
Análise Espacial dos Condicionantes da Criminalidade Violenta no Estado de Minas Gerais

Wagner Barbosa Batella, Alexandre Magno Alves Diniz

\section{INTRODUÇÃO}

A violência é um tema candente, que emerge neste início de século como um dos principais problemas enfrentados pelos habitantes das grandes cidades. Além das vítimas diretas, ela é responsável pelo sentimento de insegurança e pelo medo que afligem grande número de pessoas, alterando paisagens e comportamentos. Trata-se de um fenômeno complexo e multifacetado, que mobiliza esforços de diversas frentes, formais e informais, na busca de soluções e/ou medidas mitigadoras (FELIX, 1996 e 2002; LIMA, 2002; DINIZ, 2003).

Essa preocupação, que se agrava com as divulgações de estatísticas policiais, gerou um maior engajamento de diversas áreas do saber em estudos acerca dos fatores correlatos da violência, o que culminou numa literatura vasta e diversificada, indicando tratar-se de um fenômeno complexo.

A Geografia há algum tempo contribui para este debate, uma vez que a violência guarda consigo um forte componente espacial, que se faz notória por meio da identificação de padrões específicos em sua distribuição espacial. Ainda assim, os geógrafos avançaram muito pouco em construções teóricas que visam entender e explicar este fenômeno. Em grande medida, as contribuições destes profissionais se materializam nos trabalhos empíricos, que tratam das relações entre violência e seus condicionantes clássicos, sobretudo àqueles ligados aos aspectos sócio-econômicos, demográficos e ambientais. No geral, essas abordagens focam parte do problema, pois tendem a analisar a violência, principalmente aquela classificada nos códigos penais, e suas relações com um ou outro condicionante. Raras são as contribuições que focam o aspecto multifacetado desse problema, considerando um conjunto maior de variáveis que representariam estes condicionantes.

Uma análise mais aprofundada da literatura sobre essa temática no escopo da Geografia revela, ainda, que os condicionantes da violência não apresentam a mesma significância na sua manifestação espacial. Dessa forma, contextos espaciais distintos guardam consigo relações díspares com tais condicionantes. Em outras palavras: os condicionantes da violência adquirem relevância diferenciada de acordo com o local onde são analisados (DINIZ; BATELLA, 2004; DINIZ, 2005a; DINIZ, 2005b; BATELLA; DINIZ, 2006).

A integração desses condicionantes, com o fito de se obter uma análise mais complexa do problema da violência, encontra subsídios nos recursos oferecidos atualmente pelos Sistemas de Informações Geográficas (SIG’s) e pela Estatística Multivariada, elementos que têm proporcionado "elevado nível de precisão, eficiência e rapidez na manipulação de grande volume de dados, para fins de análise espacial e de representação gráfica de Informações Espaciais" (CASTRO, 2000, p.1).

Diante disso, o presente trabalho pretende contribuir com uma análise sobre os condicionantes dos crimes contra o patrimônio e contra a pessoa numa perspectiva espacial e, levando em conta a complexidade do fenômeno, explora diversas variáveis sugeridas pela literatura e entendidas como fatores correlatos à criminalidade. Dessa forma, a partir de fontes diversas e contando com os modernos recursos dos SIG's e de técnicas de Estatística Multivariada, este estudo apresenta, em primeiro lugar, uma análise da distribuição espacial da criminalidade violenta no Estado de Minas Gerais no ano de 2005; na sequência, buscase por meio de análises estatísticas, a elaboração de modelos preditivos que viabilizem a identificação das variáveis mais determinantes para os grupos populacionais mais afetados do Estado de Minas.

\section{CONDICIONANTES DA CRIMINALIDADE}

Sobre as teorias acerca das causas dos crimes, CERQUEIRA e LOBÃO (2004) chamam a atenção para o fato de que, desde meados do século $\mathrm{XX}$, este arcabouço teórico tem se desenvolvido em duas direções principais, quais sejam: aquelas focadas nas motivações individuais, bem como nos processos que levariam as pessoas a se tornarem criminosas; e nas tentativas de se compreender as 
relações entre taxas de criminalidade e suas variações entre diferentes culturas e organizações sociais. Em períodos anteriores, os estudos sobre o tema buscavam tão somente causas gerais para explicar o comportamento criminoso, acreditando que sua extirpação seria a solução para a criminalidade. No entanto, nos estudos atuais as propostas são mais abrangentes, sendo as maiores contribuições creditadas aos sociólogos, embora há muito contase com as colaborações de psicólogos, economistas, médicos e, mais recentemente, de geógrafos, dentre outros. Tais abordagens, em geral, têm como objeto quatro elementos: a lei, o criminoso, o alvo e o lugar (SILVA, 2004).

Pela particularidade deste trabalho, o foco recaiu sobre os elementos ligados ao lugar. Tratase de um deslocamento, na análise, das atitudes individuais, tratadas como reação ao comportamento da sociedade, para as diferentes características dos lugares no interior de cidades ou regiões, que são trabalhadas como fatores causais da criminalidade (SILVA, 2004). Ou seja, esta perspectiva busca compreender como as características de certas localidades podem influenciar indivíduos a cometer crimes ou a se tornarem vítimas.

Com base na literatura especializada, identificaram-se os fatores mais estudados como condicionantes da criminalidade. Apresenta-se, a seguir, um breve comentário sobre as relações entre estes temas e os dados de crimes violentos.

- Desenvolvimento humano

Os trabalhos de Beato (1998) e Beato e Reis (2000) discutiram a relação entre desenvolvimento humano e taxas de criminalidade. Tomandose estes textos como norteadores desta reflexão, esperar-se-ia uma correlação mais significativa entre os crimes violentos contra o patrimônio e o IDH-M. Tal expectativa é explicada pelas relações que esta categoria de crime guarda com contextos espaciais marcados por elevados indicadores de desenvolvimento. Estes ambientes são caracterizados pela coexistência de diversos fatores que contribuem para o fortalecimento dessa relação, tais como melhores condições econômicas, grandes concentrações populacionais e enfraquecimento dos mecanismos de controle social, garantindo assim mais oportunidades ao ato criminoso.

- Riqueza

A correspondência entre riqueza e crimes contra o patrimônio foi discutida por Beato (1998). O autor afirma que, contraditoriamente ao proposto em inúmeros trabalhos, a explicação mais significativa para o crime não é a pobreza, mas a riqueza. Ambientes mais prósperos são sinônimos de oportunidades para ação criminosa, uma vez que fornecem mais alvos viáveis e compensadores, além de enfraquecerem mecanismos tradicionais de controle social e vigilância.

- Desigualdade de renda

Contextos marcados por desníveis sócioeconômicos são encarados como ambientes que aproximam realidades muito díspares. Desta forma, apoiando-se nas reflexões de Briceño - León (2002), que afirma que o empobrecimento e a desigualdade são responsáveis pelo incremento da criminalidade, $o$ índice de Gini representaria uma importante medida de concentração de riquezas e, conseqüentemente, uma variável potencialmente reveladora da incidência criminal. Esperar-se-ia, então, que este descompasso econômico fosse responsável pelo desencadeamento de atos criminosos, principalmente nas grandes cidades onde pobreza e riqueza coexistem mais estreitamente (FELIX, 2002).

\section{- Infra-estrutura}

São poucos os trabalhos que versam sobre a relação entre infra-estrutura e criminalidade. Porém, esta última está ligada, também, ao problema de moradia. "A exclusão territorial faz indivíduos, famílias e comunidades particularmente vulneráveis, abrindo espaço para a violência e o conflito" (ROLNIK, 1999, p. 100). Os profundos contrastes entre condições urbanas no interior das cidades, mais do que expressar diferenças econômicas e sociais, impactam na forma e no funcionamento das cidades. Para a arquiteta Rolnik (1999), a exclusão territorial produz uma vida diária insegura e arriscada, bloqueia 
acesso a empregos, a oportunidades educacionais e culturais, que estão concentrados em enclaves pequenos e protegidos dentro das cidades. Estes contrastes contribuem para o incremento das taxas de criminalidade.

\section{- Educação}

A educação formal, ou a falta dela, é um tema comumente explorado como condicionante da criminalidade. Regiões marcadas por baixos indicadores de escolaridade podem vir a se tornar regiões onde a prática do crime seja mais constante. A relação entre educação e criminalidade pode ocorrer de forma direta ou indireta. De forma direta, por exemplo, através de uma maior propensão que grupos de indivíduos detentores de baixos níveis educacionais apresentam em recorrer à violência física para mediar conflitos e desavenças pessoais (BATELLA; DINIZ; TEIXEIRA, 2008). De forma indireta, a educação passa a ser uma pré-condição ao acesso das pessoas a uma melhor qualificação profissional e, conseqüentemente, a uma renda melhor. Baixo nível educacional, portanto, significa dificuldade de acesso à renda, ocasionada por um mercado de trabalho que exige qualificação (BRICEÑO-LEÓN, 2002; CARDIA, 2004).

\section{- Estrutura populacional}

As variáveis relacionadas à estrutura populacional freqüentemente são abordadas em estudos sobre condicionantes da criminalidade. Felix (2002) afirma que as elevadas densidades populacionais das cidades de porte elevado dão à vida um caráter anônimo, desestruturando mecanismos de controle social informal. Por sua vez, Beato (1998) discute a relação entre tamanho populacional e oportunidades, lembrando que os delitos são dependentes de oportunidades para contato social. Todas essas propostas fazem com que as maiores correlações deste tema sejam com a categoria crimes contra o patrimônio.

\section{- Imigração}

Felix (2002, p.38) afirma que em função das expectativas frustradas, as diversas privações sociais, o baixo poder aquisitivo, baixo nível de instrução, precariedade de moradia, desemprego ou ocupação em subempregos, dentre outras tantas características negativas que caracterizam um número significativo de migrantes fazem com que "o saldo migratório esteja significativamente relacionado ao crime contra o patrimônio".

\section{MÉTODOS E TÉCNICAS}

Este estudo priorizou os crimes violentos contra o patrimônio e os crimes violentos contra a pessoa registrados nos Boletins de Ocorrências (BO's) da PMMG para o ano de 2005, pois este era o período mais recente quando teve início a fase de levantamento dos dados. As categorias de crimes pesquisadas referem-se às seguintes classificações, também adotadas pela PMMG:

- crimes violentos contra o patrimônio: são os crimes que atentam contra a propriedade material (roubo, roubo a mão armada, roubo seguido de morte, roubo de veículo e extorsão mediante seqüestro);

- crimes violentos contra a pessoa: são os crimes que atentam contra a vida (homicídio consumado, homicídio tentado, estupro consumado, estupro tentado, seqüestro e cárcere privado);

A etapa seguinte foi de levantamento das variáveis que permitiram a quantificação dos temas entendidos como condicionantes da criminalidade. Diante da incompatibilidade cronológica de produções estatísticas, uma vez que os censos brasileiros são realizados a cada período de dez anos, as variáveis referem-se à última divulgação censitária, ou seja, o ano de 2000. Muitas outras variáveis, elaboradas por diversos órgãos, que não o IBGE, acompanham as produções deste instituto para elaboração de seus dados, como é caso do IDH - M, elaborado pelo PNUD/IPEA/FJP.

A opção por variáveis do ano de 2000 para análise da criminalidade violenta registrada no ano de 2005 é justificada, ainda, pelo fato de que a criminalidade pode ser entendida como um processo 
que se desenvolve num cenário sócio-econômico que necessita de um intervalo de tempo para ser construído.

Os dados sobre os condicionantes da criminalidade foram organizados em sete temas, conforme apresentado na TABELA 1. Em seguida, os temas que apresentavam mais de uma variável foram submetidos à Análise de Componentes Principais (ACP), no programa SPSS, visando reduzi-las a uma única componente com seus respectivos scores.
Segundo Castro (2000), esta técnica:

Consiste em um método de redução de um conjunto de dados multivariados em componentes, denominados principais, que minimizam a redundância existente entre as variáveis, através de transformações lineares da matriz, de tal modo que as novas variáveis geradas sejam não correlacionadas entre si, mas expressem sua variabilidade.

TABELA 1: Condicionantes da criminalidade violenta - Temas e Variáveis

\begin{tabular}{|c|c|c|}
\hline Tema & Variáveis & Fonte \\
\hline $\begin{array}{l}\text { Desenvolvimento } \\
\text { humano }\end{array}$ & IDH - M 2000 & PNUD/IPEA/FJP \\
\hline \multirow{7}{*}{ Riqueza } & Renda per Capita (R\$), 2000 & PNUD/IPEA/FJP \\
\hline & PIB Per capita (R\$), 2005 & IBGE \\
\hline & Bens de Consumo TV, 2000 & IBGE \\
\hline & Bens de Consumo Telefone, 2000 & IBGE \\
\hline & Bens de Consumo Carro, 2000 & IBGE \\
\hline & Bens de Consumo Geladeira, 2000 & IBGE \\
\hline & Bens de Consumo Computador, 2000 & IBGE \\
\hline $\begin{array}{l}\text { Desigualdade de } \\
\text { renda }\end{array}$ & Índice de GINI 2000 & PNUD/IPEA/FJP \\
\hline \multirow{4}{*}{ Infra-estrutura } & $\begin{array}{l}\text { Percentual de pessoas que vivem em domicílios com água } \\
\text { encanada, } 2000\end{array}$ & PNUD/IPEA/FJP \\
\hline & $\begin{array}{l}\text { Percentual de pessoas que vivem em domicílios com } \\
\text { energia elétrica, } 2000\end{array}$ & PNUD/IPEA/FJP \\
\hline & $\begin{array}{l}\text { Percentual de pessoas que vivem em domicílios urbanos } \\
\text { com serviço de coleta de lixo, } 2000\end{array}$ & PNUD/IPEA/FJP \\
\hline & Taxa de Urbanização 2000 & IBGE \\
\hline \multirow{3}{*}{ Educação } & Taxa de alfabetização, 2000 & PNUD/IPEA/FJP \\
\hline & Taxa bruta de freqüência à escola, 2000 & PNUD/IPEA/FJP \\
\hline & $\begin{array}{l}\text { Percentual de pessoas de } 15 \text { anos ou mais analfabetas, } \\
2000\end{array}$ & PNUD/IPEA/FJP \\
\hline \multirow{3}{*}{$\begin{array}{c}\text { Estrutura } \\
\text { populacional }\end{array}$} & População total, 2000 & PNUD/IPEA/FJP \\
\hline & População de 15 a 24 anos de idade, 2000 & PNUD/IPEA/FJP \\
\hline & Densidade demográfica, 2000 & PNUD/IPEA/FJP \\
\hline \multirow{2}{*}{ Imigração } & Imigração Inter-estadual, 2000 & IBGE \\
\hline & Imigração Intra-estadual, 2000 & IBGE \\
\hline
\end{tabular}

Fonte: do autor 
Análise Espacial dos Condicionantes da Criminalidade Violenta no Estado de Minas Gerais Wagner Barbosa Batella, Alexandre Magno Alves Diniz

Na parte de tratamento dos dados, a atenção recaiu a priori sobre dados que foram cedidos em valores absolutos pela PMMG. Estes dados foram separados e submetidos à produção de taxas brutas e corrigidas, por meio de estimadores bayesianos empíricos, a fim de se evitar as flutuações aleatórias inerentes à construção de taxas de criminalidade brutas para áreas com populações reduzidas. Adotouse a elaboração de taxas para grupos de 100.000 habitantes, como é comumente realizado em estudos desta natureza.

Os dados sobre os condicionantes da criminalidade foram organizados em sete temas, conforme apresentado na TABELA 1. Em seguida, os temas que apresentavam mais de uma variável foram submetidos à Análise de Componentes Principais (ACP), no programa SPSS, visando reduzi-las a uma única componente com seus respectivos scores. Segundo Castro (2000), esta técnica:

Consiste em um método de redução de um conjunto de dados multivariados em componentes, denominados principais, que minimizam a redundância existente entre as variáveis, através de transformações lineares da matriz, de tal modo que as novas variáveis geradas sejam não correlacionadas entre si, mas expressem sua variabilidade.

Com esta técnica, as variáveis que compõem os temas riqueza, infra-estrutura, educação, estrutura populacional e condições de vida resultaram em cinco componentes que representam seus respectivos temas. Para o tema imigração, trabalhou-se com taxas por 1.000 habitantes.

$\mathrm{O}$ passo seguinte refere-se à análise $\mathrm{e}$ apresentação dos resultados. Em primeiro lugar foram trabalhadas as informações acerca dos crimes violentos contra o patrimônio e contra a pessoa. Essas informações foram exportadas do software excel para o software MapInfo, onde realizou-se a construção de cartogramas coropléticos e modelos 3D.

Além dessas análises serão elaboradas correlações pearsonianas entre as variáveis de crimes e os temas representativos dos condicionantes da criminalidade. A análise de correlação visa medir a intensidade da relação entre duas variáveis. Segundo Gerardi e Silva (1981, p.99):

Existem muitos coeficientes de correlação em estatística, sendo o coeficiente de correlação denominado produto-momento (product moment correlation coefficient) de Karl Pearson, também conhecido por $R$ de Pearson, o mais utilizado.

\section{ANÁLISES DOS RESULTADOS}

Após a tabulação e a respectiva organização em matrizes, as taxas corrigidas de crimes violentos contra o patrimônio foram submetidas ao método de classificação denominado Sturges, com o fito de se encontrar o número e o intervalo de classes que melhor comuniquem a dinâmica espacial do fenômeno.

Considerando-se a extrema concentração de taxas superiores a 1.000 para cada grupo de 100.000 habitantes em alguns municípios do estado, optou-se por agrupá-los em uma única classe. Dessa forma, foi encontrado o número de 11 classes com intervalos iguais a 76,45. Porém, é importante mencionar que experiências na cartografia comprovam que um número de classes muito elevado prejudica o leitor na hora de distinguir as variações do fenômeno mapeado. A solução, então, foi agrupar as outras classes em pares com intervalos de 152,90. Ao final, chegou-se ao número de 6 classes, como observado no MAPA 1. 


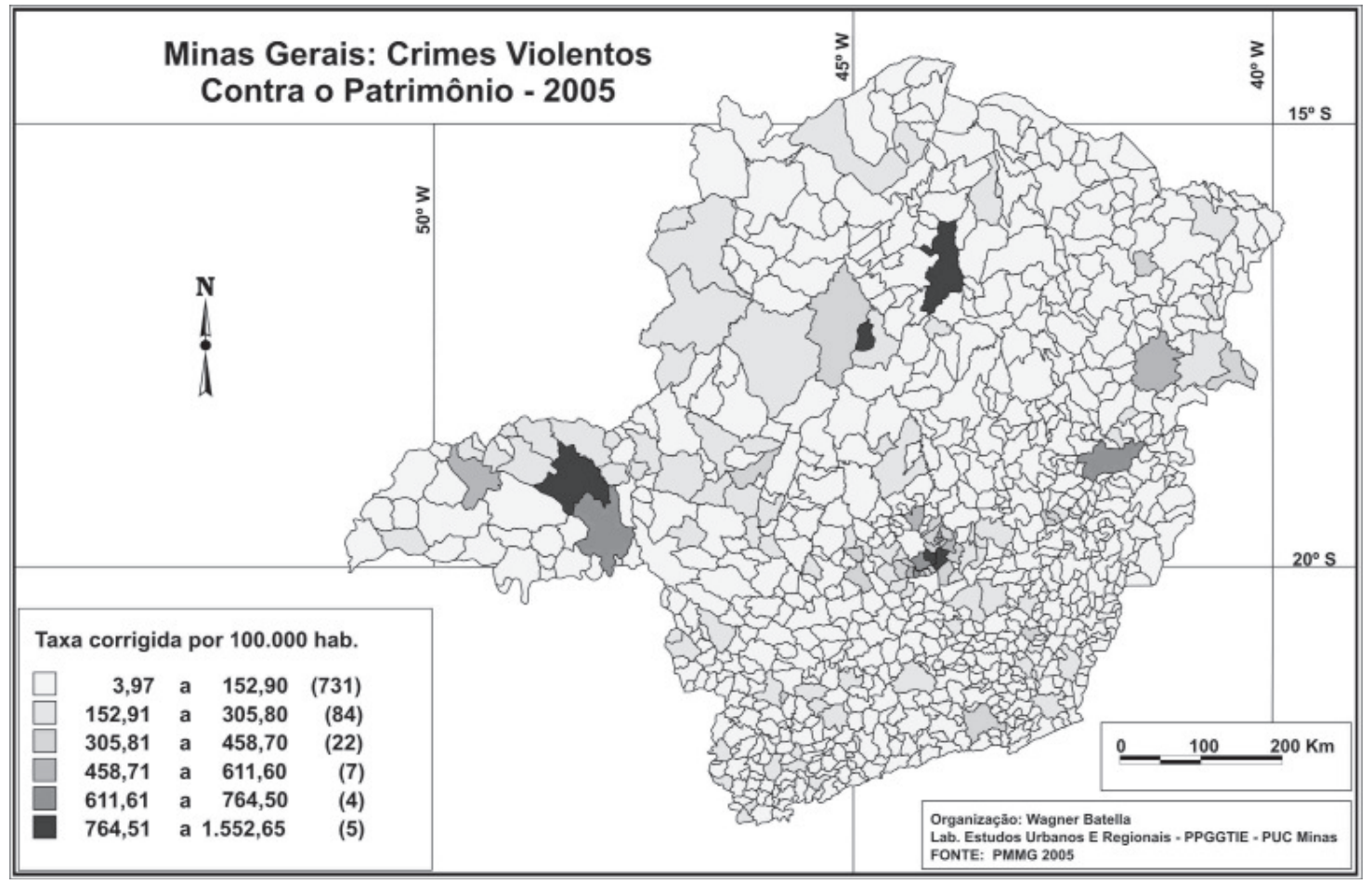

MAPA 1: Minas Gerais: Crimes Violentos Contra o Patrimônio - 2005

Fonte: Laboratório de Estudos Urbanos e Regionais - PPGGTIE - PUC Minas

Nota-se inicialmente a não homogeneidade da manifestação espacial dos crimes violentos contra o patrimônio, com o Estado apresentando significativas disparidades de incidência do fenômeno. As menores taxas, agrupadas no primeiro intervalo de classes do mapa em análise, são encontradas na imensa maioria dos municípios mineiros, totalizando 731 unidades. A população registrada nesta classe corresponde a 43\% da população total de Minas Gerais.

No outro extremo encontra-se o intervalo de classe superior, onde são encontradas as maiores taxas da modalidade de crime em análise. Neste grupo, formado por apenas cinco municípios, destacam-se importantes pólos econômicos regionais do Estado, como Uberlândia, Contagem, Belo Horizonte, Pirapora e Montes claros. Estes municípios representam $20,32 \%$ da população total de Minas e situam-se, ainda, em importantes regiões econômicas, tais como: o Triângulo Mineiro, RMBH, além dos dois últimos que se destacam na região Norte. Além dessas, destacam-se as posições dos municípios de Montes Claros e Pirapora que estão postados numa das regiões mais deprimidas do Estado, o Norte de Minas, mas desempenham papéis de destaques no contexto desta região.

Analisando as demais classes, nota-se a existência de uma divisão bastante nítida entre os outros blocos que pode ser vista iniciando-se a noroeste (municípios de Unaí, Paracatu e João Pinheiro), desenvolvendo-se em direção sudeste (passando por Curvelo, Sete Lagoas, RMBH), encaminhando-se em seguida para nordeste (Itabira, Região Metropolitana do Vale do Aço, Governador Valadares e Teófilo Otoni). Este "U" imperfeito, descrito em outros estudos sobre o Estado de Minas Gerais, é conhecido como uma linha divisória das partes norte e sul do Estado que retratam duas realidades bem díspares. $\mathrm{Na}$ porção austral encontram-se os municípios com melhores infraestruturas e economias mais consolidadas, bem como taxas mais elevadas de crimes contra o patrimônio, em detrimento da porção setentrional, onde são 
encontradas condições sócio-econômicas inferiores às médias estaduais e, concomitantemente, menores taxas de crimes contra o patrimônio.

Outro ponto importante de discussão é a grande variação das taxas. Enquanto alguns municípios como Água Boa e Piranga apresentam valores inferiores a 5 crimes para cada grupo de 100.000 habitantes, municípios como Contagem e Uberlândia concentram taxas superiores a 1.500 para cada grupo de 100.000. As maiores concentrações dessas taxas estão nos cinco municípios que constituem a classe superior do MAPA 1. O menor valor nessa classe é encontrado no município de Montes Claros (1.060,35 por 100.000 habitantes), enquanto o maior valor da classe imediatamente anterior refere-se à Governador Valadares $(749,35$ por 100.000 hab.). Esta concentração de altas taxas de criminalidade em porções específicas do espaço mineiro faz com que surjam grandes variações que podem ser melhor entendidas com o auxílio do MAPA 2, onde cada pico representa a intensidade da concentração de taxas de crimes contra o patrimônio de um município.

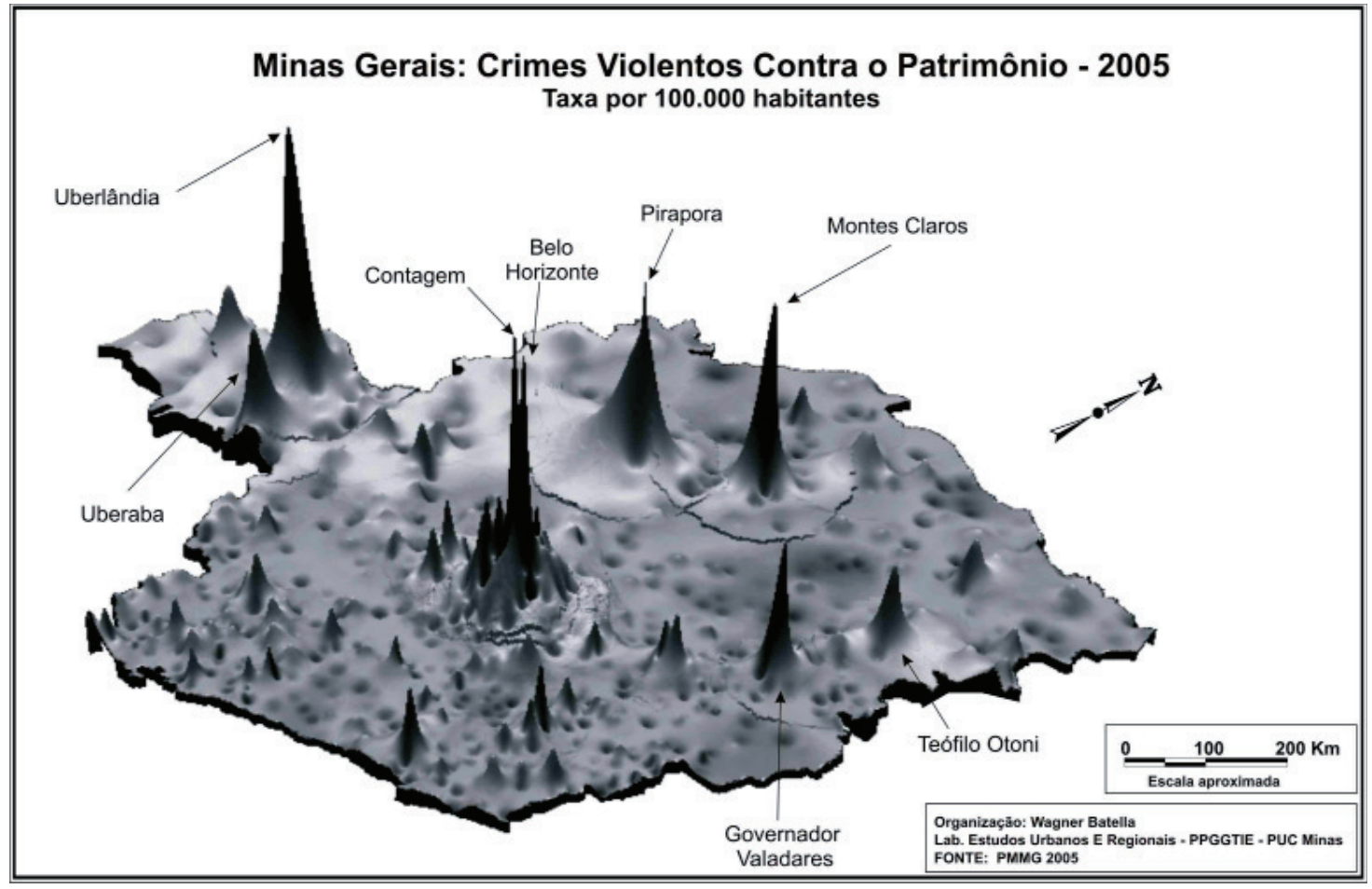

MAPA 2: Minas Gerais: “Topografia” dos Crimes Violentos Contra o Patrimônio - 2005

Fonte: Laboratório de Estudos Urbanos e Regionais - PPGGTIE - PUC Minas

Os valores da categoria de crimes contra a pessoa também foram submetidos ao método de classificação de Sturges. Após os cálculos, definiu-se um número de 12 classes com intervalos no valor de
20,81. Também aqui se repetiu o critério de redução do número de classes com o objetivo de facilitar a leitura do mapa e, ao final, definiu-se o número de 6 classes com intervalos de 41,62 (MAPA 3). 


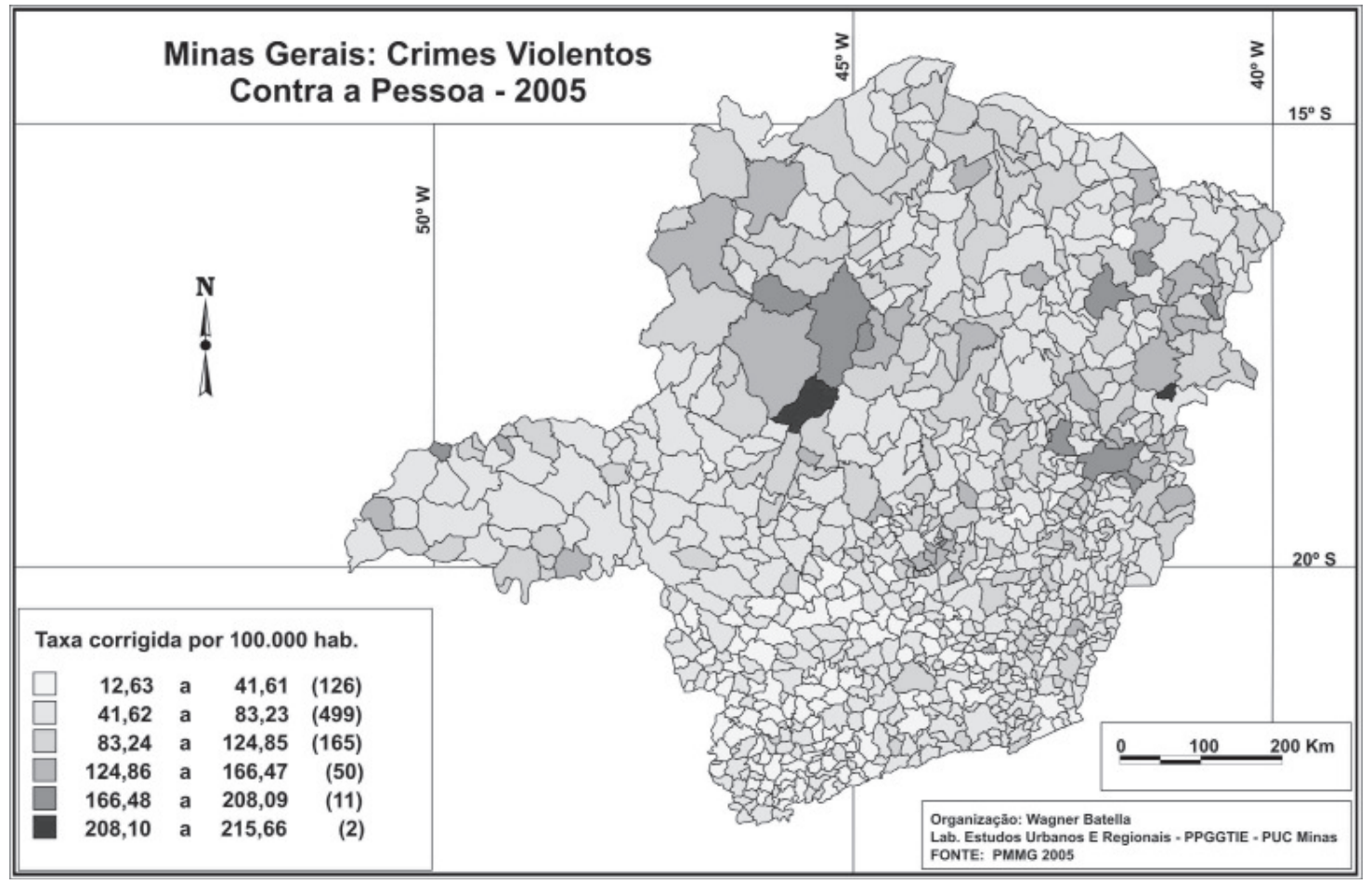

MAPA 3: Minas Gerais: Crimes Violentos Contra a Pessoa - 2005

Fonte: Laboratório de Estudos Urbanos e Regionais - PPGGTIE - PUC Minas

$\mathrm{Na}$ análise do MAPA 3, o primeiro aspecto que chama atenção é o padrão de distribuição das taxas. Há uma divisão clara do Estado, onde as maiores concentrações de crimes contra a pessoa encontram-se na porção norte. É possível notar uma linha no sentido oeste-leste, formada por municípios que apresentam as maiores taxas de incidência do fenômeno e que dividem Minas Gerais em duas partes. Esta linha tem início no lado ocidental nos municípios de Paracatu, Unaí, passando por Buritizeiro, São Gonçalo do Abaeté, Olhos D’água, São Gonçalo do Rio Preto, Peçanha, Governador Valadares e termina na porção oriental no município de Resplendor. Além destes, destacam-se os municípios de Ouro Verde de Minas, Teófilo Otoni, Araçuaí, Itaobim e Maxacalis, dentre outros.

Pode-se afirmar que o padrão espacial de distribuição é inverso ao de crimes contra o patrimônio. Enquanto neste último as maiores incidências do fenômeno estavam presentes em regiões de economia pujante, as taxas mais elevadas de crimes contra a pessoa são recorrentes em regiões menos abastadas, tais como as Mesorregiões Norte, Jequitinhonha e Mucuri. Além dessas regiões, há uma significativa concentração de taxas intermediárias de crimes contra a pessoa no entorno da RMBH, tais como Vespasiano, Santa Luzia e Ribeirão das Neves.

Além das características já mencionadas acerca da manifestação e distribuição espacial dos crimes contra a pessoa, faz-se importante destacar que, ao contrário dos crimes contra o patrimônio, onde há grande variação entre as taxas, não existem grandes discrepâncias entre os municípios mineiros no que diz respeito às taxas por 100.000 habitantes de crimes contra a pessoa. Tal afirmação fica mais evidente a partir da análise do MAPA 4, o qual não apresenta forte desnível entre os picos que representam a proporção da incidência do fenômeno. 


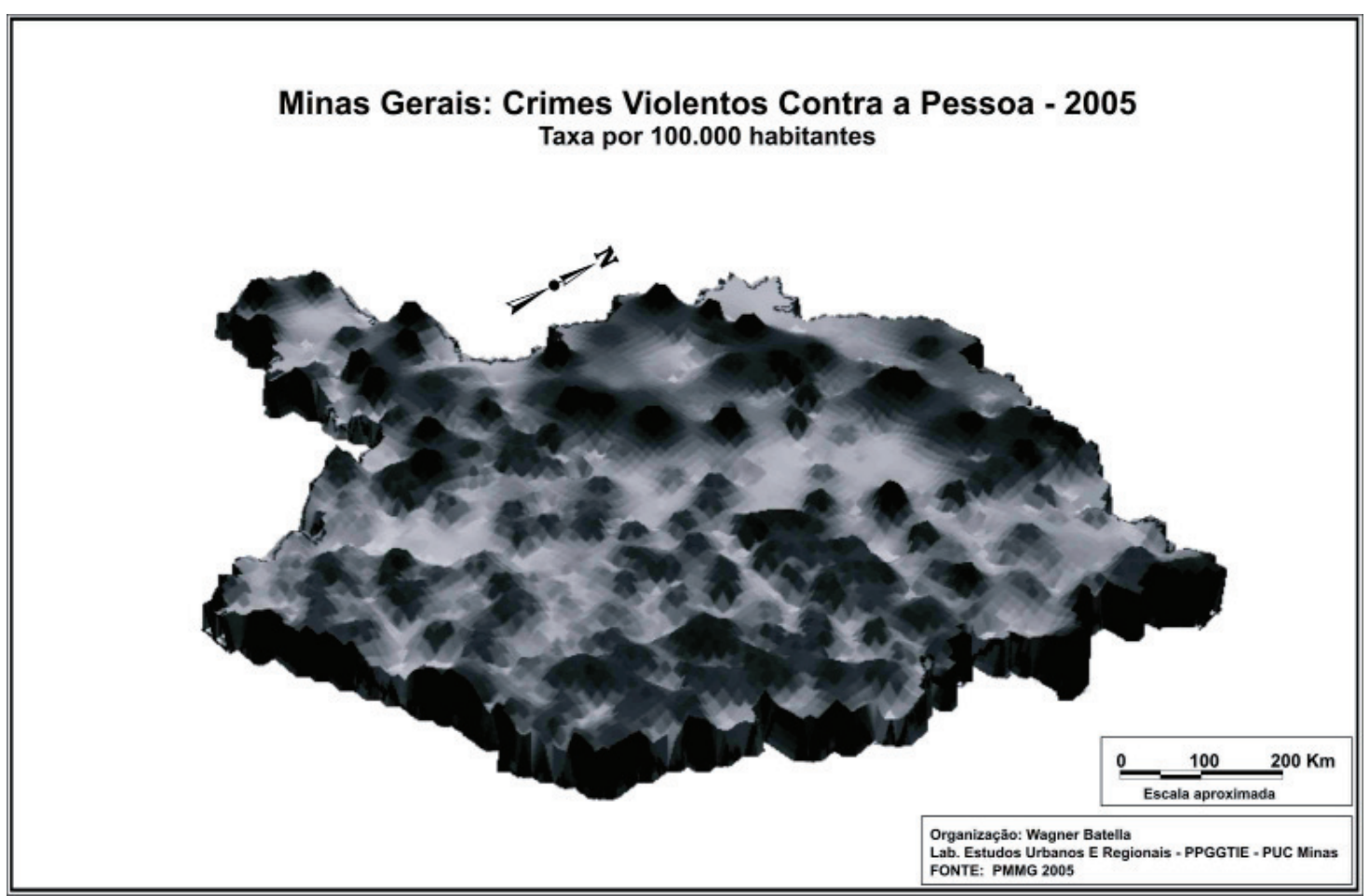

MAPA 4: Minas Gerais: “Topografia” dos Crimes Violentos Contra a Pessoa - 2005 Fonte: Laboratório de Estudos Urbanos e Regionais - PPGGTIE - PUC Minas

Após a descrição da dimensão espacial das taxas de crimes violentos contra a pessoa e contra o patrimônio, apresenta-se a investigação acerca de seus condicionantes.

Os dados foram submetidos a testes estatísticos de correlação de Pearson, com o fito de medir a intensidade da relação entre os temas sugeridos pela literatura como condicionantes da criminalidade e as categorias de crimes violentos contra o patrimônio e contra a pessoa. Os resultados são apresentados na TABELA 2, com seus respectivos níveis de significância, seguidos da discussão.

TABELA 2: Coeficientes de Correlação de Pearson dos condicionantes dos crimes violentos contra o patrimônio e contra a pessoa

\begin{tabular}{ccc}
\hline Temas & $\begin{array}{c}\text { Crimes Contra o } \\
\text { Patrimônio }\end{array}$ & $\begin{array}{c}\text { Crimes Contra a } \\
\text { Pessoa }\end{array}$ \\
\hline Desenvolvimento Humano & $0,33^{(0,01)}$ & $-0,28^{(0,01)}$ \\
Riqueza & $0,43^{(0,01)}$ & $0,26^{(0,01)}$ \\
Desigualdade de Renda & $0,01^{\mathrm{ns}}$ & $0,24^{(0,01)}$ \\
Infra-estrutura & $0,29^{(0,01)}$ & $-0,23^{(0,01)}$ \\
Educação & $0,35^{(0,01)}$ & $-0,26^{(0,01)}$ \\
Estrutura Populacional & $\mathbf{0 , 6 2}^{(\mathbf{0 , 0 1 1}}$ & $0,11^{(0,01)}$ \\
Imigração & $0,23^{(0,01)}$ & $0,07^{(0,05)}$ \\
\hline $\begin{array}{l}\text { Fonte: do autor } \\
\text { (0,0) } \text { Nível de significância } \\
\text { ns - Não significante }\end{array}$ & & \\
\hline
\end{tabular}

Sociedade \& Natureza, Uberlândia, 22 (1): 151-163, abr. 2010 
Os resultados das análises de correlações revelaram que as variáveis representativas dos condicionantes da criminalidade violenta assumem relevâncias diferenciadas entre as modalidades de crime estudadas. Os testes foram mais significativos para os crimes contra o patrimônio, onde os temas desenvolvimento humano, educação, riqueza e estrutura populacional foram os que apresentaram correlações mais fortes. Dentre esses, a estrutura populacional foi o que mais se destacou. É importante mencionar que este tema foi obtido a partir da técnica ACP a partir de três variáveis muito discutidas em estudos sobre criminalidade: população jovem (15 a 24 anos), população total e densidade demográfica.

Há um consenso na literatura especializada de que o fenômeno da criminalidade acompanhou o surgimento e a intensificação de um outro fenômeno, o da metropolização. A grande concentração de pessoas em cidades é responsável pelos abismos delineados por desigualdades sociais que intensificam as frustrações humanas e enfraquecem os mecanismos de controle social informal (FELIX, 2002). Além da dilaceração desses mecanismos de controle social, a cidade caracteriza-se como o espaço das oportunidades para atos criminosos, seja pela quantidade de alvos ou pelo anonimato que a vida urbana oferece.

\section{CONSIDERAÇÕES FINAIS}

O estudo apresentado é uma análise exploratória sobre os condicionantes da criminalidade violenta no Estado de Minas Gerais, interpretados na perspectiva geográfica. A primeira consideração a se fazer refere-se a relevância que o espaço vem ganhando nos diversos campos do saber. Nos estudos sobre a criminalidade, ele passa a ser uma variável muito importante, que vem sendo significativamente considerada na compreensão da dinâmica deste fenômeno.

A pesquisa acerca da manifestação espacial da criminalidade violenta em Minas Gerais mostrou que há uma assinatura espacial específica para cada modalidade de crime estudado. Confirmando os postulados teóricos, os crimes contra a pessoa tendem a ser mais presentes em áreas economicamente mais deprimidas do estado, em detrimento dos crimes contra o patrimônio, que são mais recorrentes em regiões mais ricas, onde há um contexto de oportunidades para os autores dos delitos. Outro aspecto discutido neste trabalho refere-se à baixa variação das taxas de crimes contra a pessoa entre os municípios mineiros, o que não ocorre com os crimes contra o patrimônio. Neste último, nota-se uma intensa concentração das maiores taxas na RMBH, no município de Uberlândia, além de outros importantes pólos regionais do estado, demonstrando-se tratar de um problema típico de grandes aglomerações urbanas.

A complexidade do fenômeno fica expressa na diversidade de temas trabalhados como condicionantes da criminalidade. Porém, as análises de correlação mostraram que o contexto urbano é o mais relacionado à criminalidade.

Durante a pesquisa, o aparato tecnológico dos SIG's permitiu testar a eficiência das geotecnologias no gerenciamento de banco de dados espaciais, onde, o cruzamento de informações e seus respectivos mapeamentos possibilitaram análises rápidas, precisas e de fácil operação. No entanto, uma grande dificuldade encontrada diz respeito às limitações das estatísticas produzidas, uma vez que nem todos os crimes são registrados. Trabalhou-se aqui com a ideia de que os dados sobre criminalidade representam uma tendência geral do fenômeno e não a sua totalidade.

\section{REFERÊNCIAS}

BATELLA, W. B.; DINIZ, A. M. A. O uso de técnicas elementares de estatística espacial no estudo da reestruturação espacial da criminalidade violenta no Estado de Minas Gerais: 1996-2003. Caderno de Geografia, Belo Horizonte, v. 16, n.26, 2006. p. 153 $-167$

BATELLA, W. B.; DINIZ, A. M. A.; TEIXEIRA, A. P. Explorando os determinantes da Geografia 
Análise Espacial dos Condicionantes da Criminalidade Violenta no Estado de Minas Gerais Wagner Barbosa Batella, Alexandre Magno Alves Diniz

do Crime nas cidades médias mineiras. Revista de Biologia e Ciências da Terra, 2008.

BEATO FILHO, C. C. Determinantes da Criminalidade em Minas Gerais. Revista Brasileira de Ciências Sociais. São Paulo, Vol.13, n.37, 1998. p. $74-89$.

BEATO FILHO, C. C.; REIS, I. A. Desigualdade, desenvolvimento socioeconômico e crime. In: HENRIQUES, R. Desigualdade e Pobreza no Brasil. Rio de Janeiro: IPEA, 2000. Cap. 13, p. $385-403$.

BRICEÑO-LEÓN, R. La nueva violencia urbana de América Latina. Sociologias. Porto Alegre, ano 4, n.8, jul./dez. 2002. p. $34-51$.

CARDIA, N. Violação dos direitos e violência: relações entre qualidade de vida urbana, exposição à violência e capital social. In: RIBEIRO, L. C. de Q. (Org.); LAGO, L. C. do L.; AZEVEDO, S.; SANTOS JUNIOR, O. A. (Col.). Metrópoles: entre a coesão e a fragmentação, a cooperação e o conflito. Rio de Janeiro: Fundação Perseu Abramo, 2004. p. $325-356$.

CASTRO, J. F. M. Caracterização espacial do sul de Minas e "entorno" utilizando-se o modelo potencial e a análise de fluxos em sistemas digitais: uma proposta metodológica. 2000. $157 \mathrm{f}$. Tese (Doutorado em Geografia - Análise da Informação Espacial) IGCE/Instituto de Geociências e Ciências Exatas, Universidade Estadual Paulista, Rio Claro, 2000.

CERQUEIRA, D.; LOBÃO, W. Determinantes da Criminalidade: Arcabouços Teóricos e Resultados Empíricos. Dados - Revista de Ciências Sociais. Rio de Janeiro, vol.47, n.2, 2004. p.233 - 269.

DINIZ, A. M. A. A geografia do medo: Reflexões sobre o sentimento de insegurança em Belo Horizonte. O Alferes, v.18, ed. especial, out. 2003. p. $119-133$.

DINIZ, A. M. A.; BATELLA, W. B. Criminalidade Violenta nas Regiões de Planejamento de Minas
Gerais: Uma Abordagem Quantitativa. Caderno de Geografia. Belo Horizonte, v. 14, n. 23, 2. Sem. 2004. p. $51-72$,

DINIZ, A. M. A. Migração, Desorganização Social e Violência Urbana em Minas Gerais. Revista Ra'Ega. Curitiba: n.9, 2005a. p. $09-23$.

DINIZ, A. M. A. Violência Urbana nas Cidades Médias Mineiras: Fim de um Mito? In: MOURA, A. M. S.; SENA FILHO, N. (Org.) Cidades: Relações de Poder e Cultura Urbana. Goiânia: Vieira, 2005b. p. $133-170$.

FELIX, S. A. A Geografia do Crime Urbano: aspectos teóricos e o caso de Marília. 1996. 322f. Tese (Doutorado) - Universidade Estadual Paulista Júlio Mesquita, Instituto de Geociências, Rio Claro.

FELIX, S. A. Geografia do Crime: Interdisciplinaridade e Relevância. Marília: Unesp Marília Publicações, 2002.

GERARDI, L. H. de O.; SILVA, B. C. N. Quantificação em geografia. São Paulo: DIFEL, 1981.

GRIFFITH, D. A.; AMRHEIN, C. G. Multivariate statistical analysis for geographers. New Jersey: Prentice-Hall, 1997.

LIMA, R. S. Criminalidade Urbana: conflitos sociais e criminalidade urbana dos homicídios cometidos no Município de São Paulo. São Paulo: Sicurezza, 2002.

MINGOTI, S. A. Análise de dados através de métodos de estatística multivariada: uma abordagem aplicada. Belo Horizonte: Ed. UFMG, 2005.

ROLNIK, R. Exclusão territorial e violência. São Paulo em perspectiva. vol. 13, n.4, 1999. p. $100-$ 111.

SANTOS, A. E.; RODRIGUES, A. L.; LOPES, D. L. Aplicações de Estimadores Bayesianos Empíricos para Análise Espacial de Taxas de 
Mortalidade. In: VII SIMPÓSIO BRASILEIRO DE GEOINFORMÁTICA, 2005, Campos do Jordão. Anais... Campos do Jordão: INPE, 2005. p. 300 309.

SILVA, B. F. A. Coesão Social, Desordem Percebida e Vitimização em Belo Horizonte. 2004. $80 \mathrm{f}$. Dissertação (Mestrado em Sociologia) - Faculdade de Filosófica e Ciências Humanas, Universidade Federal de Minas Gerais, Belo Horizonte. 